\title{
Ultrafast Kinetics of Supramolecules with a Ru(II)- or Os(II)-polypyridyl Light Absorber, cis-Rh(III)Cl 2 -polypyridyl Electron Collector, and 2,3-bis(2-pyridyl)pyrazine Bridge
}

\author{
David F. Zigler, ${ }^{\mathrm{a}, *}$ Zachary A. Morseth, ${ }^{\mathrm{a}}$ Travis A. White, ${ }^{\mathrm{b}}$ Theodore R. Canterbury, ${ }^{\mathrm{b}}$ Hannah J. Sayre, ${ }^{\mathrm{b}}$ \\ José Á. Rodríguez-Corrales, ${ }^{\mathrm{b}}$ M. Kyle Brennaman, ${ }^{\mathrm{a}}$ Karen J. Brewer, ${ }^{\mathrm{b}, \sharp}$ and John M. Papanikolas ${ }^{\mathrm{a}, *}$ \\ ${ }^{a}$ University of North Carolina at Chapel Hill, Caudill, Kenan and Murray Laboratories, Department of Chemistry, \\ CB\#3290, Chapel Hill, NC 27599, U.S.A. \\ ${ }^{\mathrm{b}}$ Department of Chemistry, Virginia Tech, Blacksburg, VA 24061-0212 (USA) \\ *Towhom correspondence should be addressed:dzigler@calpoly.edu,john_papanikolas@unc.edu \\ *Deceased October 24, 2014
}

\begin{abstract}
The femtosecond transient absorption spectra (fsTA) and excited state kinetics for a series of six structurally related mixed-metal polypyridyl supramolecules are reported. Each complex consists of one or two light absorbers (LA) with $\mathrm{Ru}(\mathrm{II})$ or Os(II) centers attached to a $\mathrm{Rh}$ (III)centered electron collector (EC) by an aromatic bridging ligand (BL). The resulting bimetallic and trimetallic complexes have LA-BL-EC and LA-BL-EC-BL-LA architectures, respectively. Excitation at $470 \mathrm{~nm}$ light populates metal-to-bridging ligand charge transfer states (MLCT), showing a transient absorption band near $380 \mathrm{~nm}$ due to $\pi \rightarrow \pi^{*}$ transitions of a bridging ligandlocalized radical anion and a transient bleach around $525 \mathrm{~nm}$ resulting from formal oxidation of the LA metal in the excited state. Loss of the ligand localized radical signal during the first $10 \mathrm{ps}$ reflects conversion of the excited state population from an MLCT state into metal-to-metal (i.e. $\mathrm{M}(\mathrm{d} \pi)$-to-Rh(d $\left.\sigma^{*}\right)$ ) charge transfer states (MMCT). Each complex shares a similar ultrafast component, indicating that the kinetics governing MLCT $\rightarrow$ MMCT population transfer do not depend on the nature of the LA. Return to the ground state, however, is strongly LA dependent and controlled by the free-energy difference between the MMCT state and ground state, as well as an associated large reorganization energy.
\end{abstract}

\section{Introduction}

Excited state electron transfer (ET) in supramolecular donor-acceptor systems is centrally important to rationally designing photochemical molecular devices [1-3]. For strongly coupled systems, such as those in which the photo-excited donor and acceptor share a $\pi$-system, the rate of electron transfer can be extremely fast, requiring methods with femtosecond resolution $\left(10^{-15}\right.$ s) [4-8]. We have used broadband femtosecond transient absorption spectroscopy (fsTA) to examine the excited state dynamics for a series of $\mathrm{Ru} / \mathrm{Rh}$ and $\mathrm{Os} / \mathrm{Rh}$ mixed-metal supramolecules. The metal centers are connected by the bis-bidentate bridging ligand 2,3-bis(2pyridyl)pyrazine (dpp), resulting in a supramolecular donor-acceptor system.

Previous reports of the excited state properties of these systems based on steady-state spectroscopy and electrochemistry have put forth the dynamical picture shown in Fig. 1 for $\left[\mathrm{Ru}(\mathrm{bpy})_{2}(\mathrm{dpp}) \mathrm{RhCl}_{2}(\text { phen })\right]^{3+}$ (RuBRh, bpy $=2,2^{\prime}$ '-bipyridine, phen = 1,10-phenanthroline $)$. Strong electronic absorption bands in the visible region of the spectrum are assigned to metal $(\operatorname{Ru}(\mathrm{d} \pi))$-to-ligand $\left(\mathrm{dpp}\left(\pi^{*}\right)\right)$ charge transfer transitions (MLCT). From electrochemistry, the lowest unoccupied orbital (LUMO) is $\mathrm{Rh}^{\mathrm{III}}\left(\mathrm{d} \sigma^{*}\right)$, suggesting a low-lying metal $(\mathrm{Ru}(\mathrm{d} \pi))$-to$\operatorname{metal}\left(\mathrm{Rh}\left(\mathrm{d} \sigma^{*}\right)\right)$ charge transfer state (MMCT) and thus favorable conditions for photo-initiated electron transfer $\left(k_{E T}\right)$ [9-20]. The magnitude of $k_{E T}$ was inferred from a static quenching model that compares the mixed-metal complexes to the $\mathrm{Rh}$-free analogs, e.g. $\left[\operatorname{Ru}(\text { bpy })_{2}(\mathrm{dpp}) \mathrm{Ru}(\mathrm{bpy})_{2}\right]^{4+},(\mathbf{R u B})_{2}$. This model leads to the conclusion that (i) $k_{E T}$ to form the 
MMCT state is slow with respect to relaxation of the MLCT state, (ii) return to the ground state is dominated by $k_{n r}$, and (iii) back electron transfer $\left(k_{b E T}\right)$ to the ground state is faster than can be observed with nanosecond resolution spectroscopy [11,21-26].

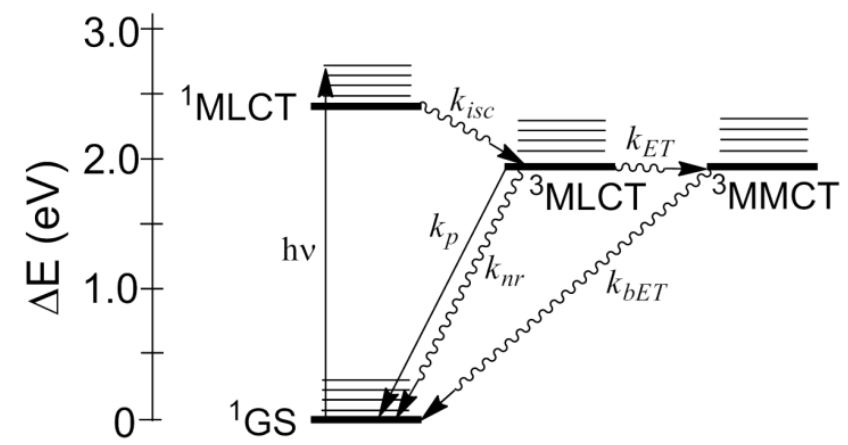

Fig. 1. Jablonski diagram illustrating singlet ground state $\left({ }^{1} \mathrm{GS}\right)$, metal-to-ligand charge transfer state $\left({ }^{1} \mathrm{MLCT}\right)$, triplet ${ }^{3} \mathrm{MLCT}$ and triplet metal-to-metal charge transfer state $\left({ }^{3} \mathrm{MMCT}\right)$ energies for the compound $\left[\mathrm{Ru}(\mathrm{bpy})_{2}(\mathrm{dpp}) \mathrm{RhCl}_{2} \text { (phen) }\right]^{3+}$. Rate constants refer to radiative $\left(k_{r}\right)$, non-radiative $\left(k_{n r}\right)$, excited state electron transfer $\left(k_{E T}\right)$ and back electron transfer from $\mathrm{Rh}^{\mathrm{II}}$ to $\mathrm{Ru}^{\mathrm{III}}$ to regenerate the ${ }^{1} \mathrm{GS}\left(k_{b E T}\right)$.

We present the results of photophysical measurements made during the first nanosecond following visible light excitation for a series of mixedmetal supramolecular complexes (Chart 1) using femtosecond transient absorption spectroscopy. In contrast to the previous reports, we find that electron transfer to generate the MMCT state is fast $\left(k_{E T}{ }^{-1}=3\right.$ 7 ps) and that return to ground state occurs predominantly through the back electron transfer pathway $\left(k_{b E T}\right)$ rather than relaxation of the MLCT state $\left(k_{p}, k_{n r}\right)$.

\section{Experimental:}

2.1. Materials: Chloride hexafluorophosphate $\left[\left\{\mathrm{Ru}(\mathrm{bpy})_{2}(\mathrm{dpp})\right\}_{2} \mathrm{RhCl}_{2}\right]^{5+}$ $\left[\left\{\mathrm{Os}(\mathrm{bpy})_{2}(\mathrm{dpp})\right\}_{2} \mathrm{RhCl}_{2}\right]^{5+}$ $\left[\mathrm{Ru}(\mathrm{bpy})_{2}(\mathrm{dpp}) \mathrm{RhCl}_{2}(\mathrm{phen})\right]^{3+}$ $\left[\{\mathrm{Os}(\mathrm{tpy}) \mathrm{Cl}(\mathrm{dpp})\}_{2} \mathrm{RhCl}_{2}\right]^{3+}$ [Os(tpy)Cl(dpp)OsCl(tpy) $]^{2+}$ salts and/or $\left((\mathbf{R u B})_{2} \mathbf{R h}\right)$, $\left((\mathbf{O s B})_{2} \mathbf{R h}\right)$,
Chart 1. Mixed-metal supramolecular complexes studied by fsTA ${ }^{a}$

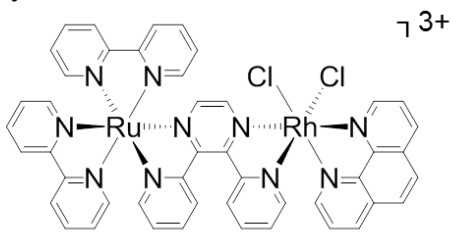

$\left[\mathrm{Ru}(\mathrm{bpy})_{2}(\mathrm{dpp}) \mathrm{RhCl}_{2}(\text { phen })\right]^{3+}=\mathbf{R u B R h}$

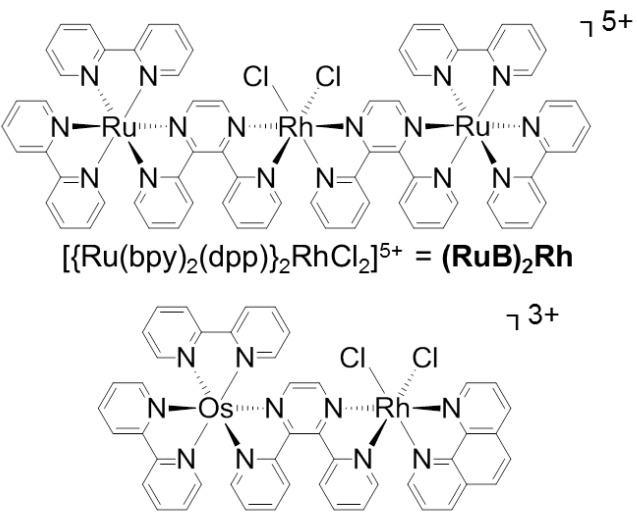

$\left[\mathrm{Os}(\mathrm{bpy})_{2}(\mathrm{dpp}) \mathrm{RhCl}_{2}(\text { phen })\right]^{3+}=\mathbf{O s B R h}$
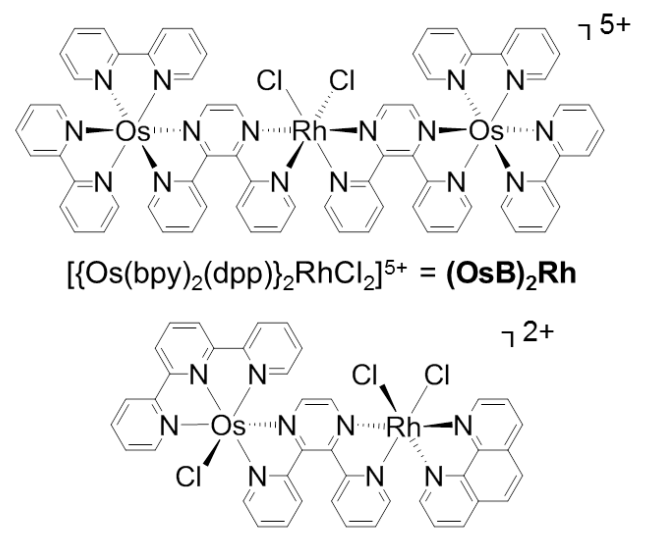

$\left[\mathrm{OsCl}(\mathrm{tpy})(\mathrm{dpp}) \mathrm{RhCl}_{2}(\text { phen })\right]^{2+}=$ OsTRh

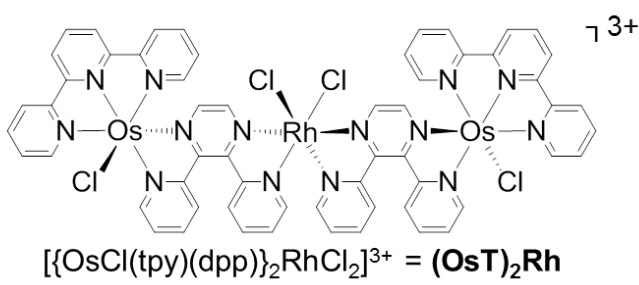

$\left[\{\mathrm{OsCl}(\mathrm{tpy})(\mathrm{dpp})\}_{2} \mathrm{RhCl}_{2}\right]^{3+}=(\mathrm{OsT})_{2} \mathrm{Rh}$

${ }^{a}$ femtosecond transient absorption spectroscopy, bpy $=2,2^{\prime}$-bipyridine, tpy $=2,2^{\prime}, 6^{\prime}, 2^{\prime \prime}$-terpyridine, $\mathrm{dpp}=2,3$-bis(2-pyridyl)pyrazine

(RuBRh), $\quad\left[\mathrm{Os}(\mathrm{bpy})_{2}(\mathrm{dpp}) \mathrm{RhCl}_{2} \text { (phen) }\right]^{3+}$

(OsBRh), $\left((\mathbf{O s T})_{2} \mathbf{R h}\right), \quad\left[\mathrm{Os}(\mathrm{tpy}) \mathrm{Cl}(\mathrm{dpp}) \mathrm{RhCl}_{2}(\text { phen })\right]^{2+} \quad($ OsTRh $), \quad$ and $\left((\mathbf{O s T})_{2}\right)$ are prepared as previously described (bpy $=2,2^{\prime}-$ bipyridine, $\mathrm{dpp}=2,3$-bis(2-pyridyl)pyrazine, phen $=1,10$-phenanthroline, tpy $=2,2^{\prime}, 6^{\prime}, 2^{\prime \prime}$ terpyridine) [4,11,24-30]. Samples for optical spectroscopy are prepared by dissolving the 
complex in water (HPLC grade, Fisher) or acetonitrile (anhydrous, spectroscopic grade, Fisher), transferred to air-tight, $2 \mathrm{~mm}$ pathlength cuvettes, and deoxygenated by sparging with ultrapure argon for $40 \mathrm{~min}$. Steady-state electronic spectra, nanosecond time-resolved photoluminescence, and extensive electrochemical characterization all have been reported previously $[4,11,24-30]$.

2.2. Electronic Absorption Spectroscopy: Steady state electronic absorption spectra are from either an Agilent 8453 diode array spectrophotometer (UV-Vis region), or from a Varian-Cary 5000 dual beam scanning spectrophotometer (UV-Vis-NIR). Steady state electronic absorption spectra are presented in the Supporting Information for comparison to the TA spectra, Fig. S1.

2.3. Spectroelectrochemistry: Spectroelectrochemical analyses are performed using previously described methods [26,29]. Two different spectroelectrochemical cell designs were used and gave comparable results. The first is a two-compartment H-cell design with each compartment (working and auxiliary) separated by a porous glass frit and with a $1 \mathrm{~cm}$ pathlength quartz cuvette at the bottom of the working compartment [26]. Carbon cloth is used for the auxiliary electrode, $\mathrm{Pt}$ mesh for the working electrode, and a $\mathrm{Ag} / \mathrm{AgCl}$ half-cell as the reference electrode $\left(3 \mathrm{M} \mathrm{NaCl}(a q) ; \mathrm{Fc}^{+/ 0}=+0.45 \mathrm{~V}\right)$. Analyte solutions are $0.1 \mathrm{M} \mathrm{Bu}_{4} \mathrm{NPF}_{6}$ supporting electrolyte in acetonitrile, and are under a constant Ar atmosphere at room temperature. Finally, the working compartment contains the working electrode, reference electrode, Ar gas inlet, and analyte solution. An alternative cell design uses an optically transparent thin layer electrode (OTTLE) formed by sandwiching a gold mesh working electrode with quartz plates [29]. The analyte solution (prepared as above) in a shallow Pyrex dish is placed in the spectrometer such that when the OTTLE cell is suspended in the light path, the bottom is immersed in the analyte reservoir. Analyte solution is carried into the light path by capillary action, and reference and auxiliary electrodes also are immersed in the reservoir. For either cell, a constant potential is applied using a Bioanalytical System (BAS) Epsilon potentiostat and spectra are collected periodically to monitor changes with potential.

2.4. nsTA: Transient absorption spectra on the nanosecond time scale were obtained using previously reported procedures [31]. Briefly, solutions in a $1 \mathrm{~cm}$ pathlength cell were pumped with $532 \mathrm{~nm}$ light ( $5 \mathrm{~mJ}, 0.5 \mathrm{~mm}$ spot, 5-7 ns FWHM) and probed at $90^{\circ}$ using pulsed output from a $450 \mathrm{~W}$ xenon arc lamp. Transmitted probe light was passed through a monochromator and detected at a PMT. Single wavelength decay data were acquired for a minimum of 50 pulses and averaged.

2.5. fsTA: The femtosecond transient absorption instrument has been described previously [32]. Briefly, the output $(775 \mathrm{~nm}, 200 \mathrm{fs}, 1.4 \mathrm{~mJ} /$ pulse $)$ from a $1 \mathrm{kHz}$ chirped-pulsed amplified laser system (Clark-MXR CPA 2010) is divided. A portion of the output pumps an optical parametric amplifier (TOPAS-C) to generate pump pulses $(\sim 100 \mathrm{~nJ})$ tunable throughout the visible and infrared regions of the spectrum. The remaining portion or the output is used to generate supercontinuum white light in a translated $\mathrm{CaF}_{2}$ window (340 to $750 \mathrm{~nm}$ ). The pump pulse timing relative to the white light probe pulse is controlled with a retroreflector mounted on a translation stage, and the relative polarization is set at magic angle using a broadband halfwave plate. Following interaction at the sample $(w=150 \mu \mathrm{m})$, transmitted white light is 
collected, diffracted and projected onto a fast camera detector (EOS), where the raw signal is collected (12000 to 36000 measurements per time point) and averaged using a control panel custom built in LabView. The absorption spectra are obtained by chopping the pump pulse train at $500 \mathrm{~Hz}$ and measuring the difference in the white light intensity when the pump is "on" versus when it is "off." Chirp in the white light pulse is corrected for by measuring the spectrally resolved cross-correlated signal in $\mathrm{CCl}_{4}$, fitting the resulting phase correlated signal to a polynomial function, and adjusting the time zero at each wavelength channel based on that polynomial. Steady-state absorption spectra obtained after the TA measurements were unchanged from those taken beforehand.

2.6. Fitting Spectral Decay Kinetics: Decay of induced absorptions $(\Delta \mathrm{A}>0)$ or ground state bleaches $(\Delta \mathrm{A}<0)$ arising from photoexcitation are fit to exponential decay functions such as,

$$
\Delta \mathrm{A}(t)=A_{1} e^{-\left(\tau_{1}^{-1} t\right)}+A_{2} e^{-\left(\tau_{2}^{-1} t\right)}+A_{3} e^{-\left(\tau_{3}^{-1} t\right)} \quad \text { Eq. } 1
$$

where the parameters of pre-exponential amplitude $\left(A_{i}\right)$ and time constant $\left(\tau_{i}\right)$ are found by nonlinear least squares (Levenberg-Marquardt) using Origin 9.1 (OriginLab, Northhampton, MA).

\section{Results and Discussion}

In this work we build a new mechanistic framework for excited state evolution dynamics for a series of mixed-metal supramolecules. First we focus on the $\mathrm{Ru} / \mathrm{Rh}$ heterobimetallic $\left[\mathrm{Ru}(\mathrm{bpy})_{2}(\mathrm{dpp}) \mathrm{RhCl}_{2} \text { (phen) }\right]^{3+}$ (RuBRh) to discuss the origin of spectral features observed by broadband transient absorption spectroscopy as well as the kinetics of excited state evolution (Section 3.1). These features are shown to be general for other mixed-metal complexes examined as part of this study. An energetic framework is then developed to explain the observed kinetics (Section 3.2), and finally a comparison between mixed-metal systems is made by extending this framework to the other complexes displayed in Chart 1 (Section 3.3).

\subsection{Spectral Evolution of $\boldsymbol{R u B R h}$}

Excited state evolution was followed with transient absorption spectroscopy after excitation into the MLCT manifold with a $470 \mathrm{~nm}$ femtosecond laser pulse. The transient absorption spectra obtained for RuBRh in acetonitrile are presented in Fig. 2. Three main spectral features are observed: a moderate absorption near $380 \mathrm{~nm}$ associated with $\pi \rightarrow \pi^{*}$ transitions of a dpplocalized radical anion [30], a prominent bleach of the GS $\rightarrow$ MLCT band at $501 \mathrm{~nm}$, and a weak broad absorption extending red of $600 \mathrm{~nm}$ that is assigned to various $\pi \rightarrow \pi^{*}$ transitions and ligand-to-metal transitions involving the formally oxidized $\mathrm{Ru}[33,34]$. Transient spectra collected in aqueous solution were similar, with small differences in peak positions. These data and parameters used to fit decays of the excited state spectra in water or acetonitrile are summarized in Table 1. While much of the spectrum shows little or no evolution on the picosecond time scale, the intensity of the near-UV absorption relative to the visible bleach $\left(\left|\Delta \mathrm{A}^{n \mathrm{UV}}\right| /\left|\Delta \mathrm{A}^{\text {vis }}\right|\right.$ ) decreases from $\sim 0.5$ at earliest times to $\sim 0.25$ with a 7 ps time constant (Fig. 2). Other Ru(II) polypyridyl chromophores show pronounced decrease in the near-UV absorption upon excited state oxidation due to loss of the ligand localized radical anion component associated with the MLCT state [32,35]. As will be shown below, the changes seen with RuBRh are also consistent with oxidation of the MLCT state. 

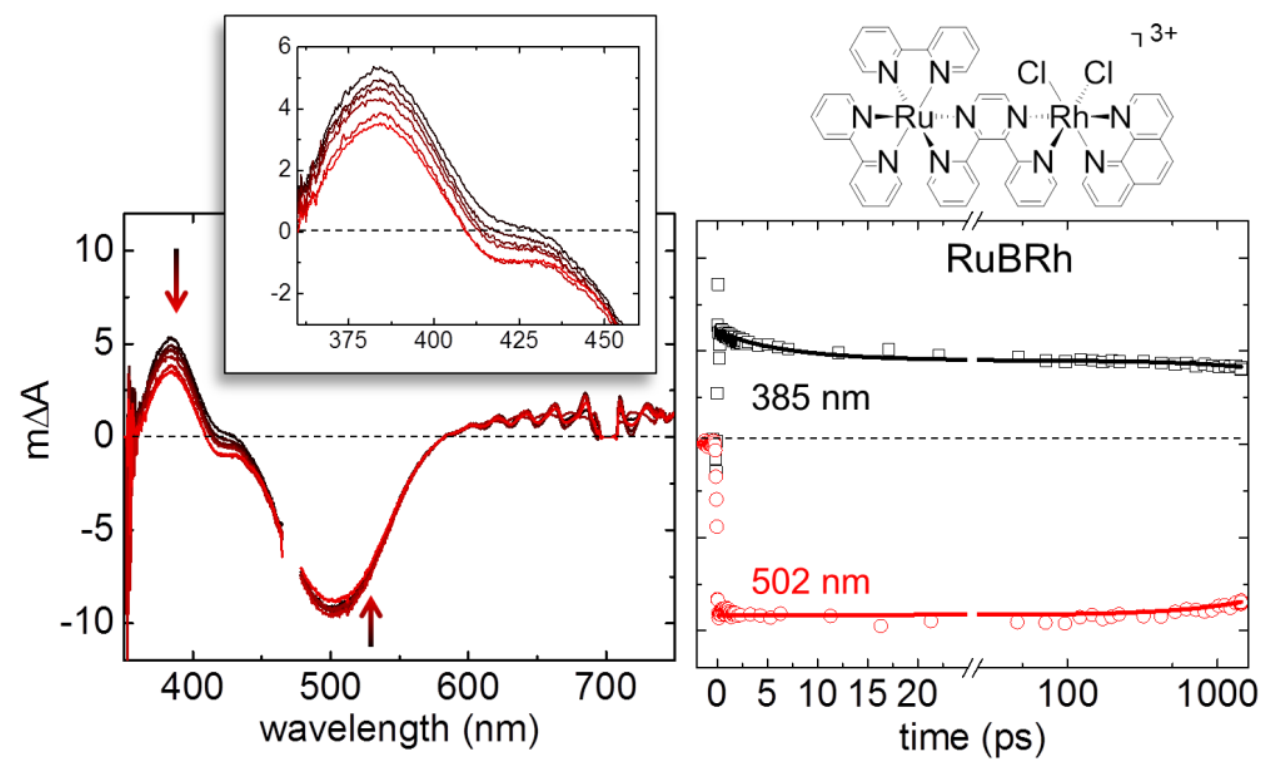

Fig. 2. (left) Transient absorption spectra of $\left[\mathrm{Ru}(\mathrm{bpy})_{2}(\mathrm{dpp}) \mathrm{RhCl}_{2} \text { (phen) }\right]^{3+}$ obtained in deaerated, room-temperature acetonitrile, following $470 \mathrm{~nm}$ excitation (110 nJ, $150 \mu \mathrm{m} \mathrm{spot})$. The inset shows a zoomed in region of the spectrum highlighting early time changes to the spectrum. The spectra (from black to red) were taken at $600 \mathrm{fs}, 2 \mathrm{ps}, 5 \mathrm{ps}, 10 \mathrm{ps}, 100 \mathrm{ps}$, and 1.2 ns. The fine structure around $775 \mathrm{~nm}$ is a result of instability in the supercontinuum in this region of the spectrum. (right) Decays of the maximal absorption ( $\square$ ) and minimal bleach (O) are plotted. Also shown are fits of the decays to multiexponential functions (lines).

Table 1. Time constants and amplitudes from fits to the decay of photoexcited $\left[\mathrm{Ru}(\mathrm{bpy})_{2}(\mathrm{dpp}) \mathrm{Ru}(\mathrm{bpy})_{2}\right]^{4+},\left[\mathrm{Ru}(\mathrm{bpy})_{2}(\mathrm{dpp}) \mathrm{RhCl}_{2}(\mathrm{phen})\right]^{3+}$, and $\left[\left\{\mathrm{Ru}(\mathrm{bpy})_{2}(\mathrm{dpp})\right\}_{2} \mathrm{RhCl}_{2}\right]^{5+a}$.

\begin{tabular}{|c|c|c|c|c|c|c|c|c|c|}
\hline Compound & Solvent $^{a}$ & $\lambda^{\mathrm{ex}}(\mathrm{nm})$ & $\lambda^{\mathrm{prb}}(\mathrm{nm})$ & $\mathrm{A}_{1}{ }^{b}$ & $\tau_{1}(\mathrm{ps})$ & $\mathrm{A}_{2}^{b}$ & $\tau_{2}(\mathrm{ps})$ & $\mathrm{A}_{3}{ }^{b}$ & $\tau_{3}^{c}(\mathrm{~ns})$ \\
\hline$(\mathrm{RuB})_{2}{ }^{d}$ & $\mathrm{MeCN}$ & 532 & 550 & -- & -- & -- & -- & -1 & $125^{d}$ \\
\hline \multirow[t]{4}{*}{ RuBRh } & $\mathrm{MeCN}$ & 470 & 385 & 0.17 & $7.2(0.7)$ & -- & -- & 0.49 & $18^{d}$ \\
\hline & & & 502 & -- & -- & -- & -- & -1 & $18^{d}$ \\
\hline & $\mathrm{H}_{2} \mathrm{O}$ & 470 & 384 & 0.27 & $2.5(0.1)$ & -- & -- & 0.45 & $9.1^{d}$ \\
\hline & & & 506 & -- & -- & -- & -- & -1 & $9.1^{d}$ \\
\hline \multirow[t]{4}{*}{$(\mathrm{RuB})_{2} \mathbf{R h}$} & $\mathrm{MeCN}$ & 470 & 380 & 0.11 & $3.1(0.5)$ & 0.20 & $156(16)$ & 0.71 & $16^{d}$ \\
\hline & & & 519 & -- & -- & -0.18 & $196(20)$ & -0.82 & $16^{d}$ \\
\hline & $\mathrm{H}_{2} \mathrm{O}$ & 470 & 380 & 0.27 & $3.1(0.2)$ & 0.09 & $133(48)$ & 0.43 & $7.0^{d}$ \\
\hline & & & 519 & -- & -- & -0.08 & $133(48)$ & -0.92 & $7.0^{d}$ \\
\hline
\end{tabular}

\footnotetext{
${ }^{a} \mathrm{dpp}=2,3$-bis(2-pyridyl)pyrazine, bpy $=2,2^{\prime}$-bipyridine, phen $=1,10$-phenanthroline, $\mathrm{MeCN}=$ acetonitrile

${ }^{b}$ Amplitudes are normalized to the sum of those contributing to decay of the MLCT bleach.

Error for each was \pm 0.01

${ }^{c}$ long times were fixed at literature values

${ }^{d}$ Ref. [29]
} 
The transient spectra of RuBRh are interpreted with the help of spectroelectrochemistry and by comparing these spectra to a model complex that lacks a Rh center, $(\mathbf{R u B})_{2}$. The ground state of both assemblies has a $\mathrm{Ru}(\mathrm{II})$-centered light absorber. Oxidation of $\mathbf{R u B R h}$ and $(\mathbf{R u B})_{2}$ to generate $\left[\mathrm{Ru}^{\mathrm{III}}(\mathrm{bpy})_{2}(\mathrm{dpp}) \mathrm{Rh}^{\mathrm{III}} \mathrm{Cl}_{2}(\mathrm{phen})\right]^{4+}$ and $\left[\mathrm{Ru}^{\mathrm{III}}(\mathrm{bpy})_{2}(\mathrm{dpp}) \mathrm{Ru}^{\mathrm{III}}(\mathrm{bpy})_{2}\right]^{6+}$, respectively, causes a bleach of the MLCT absorption band, shown as the dotted lines in Fig. 3. Reduction of $(\mathbf{R u B})_{2}$ to $\left[\mathrm{Ru}^{\mathrm{II}}(\mathrm{bpy})_{2}\left(\mathrm{dpp}^{\cdot-}\right) \mathrm{Ru}^{\mathrm{II}}(\mathrm{bpy})_{2}\right]^{3+}$ (dashed line), which has a pair of absorptions at 400 $\mathrm{nm}$ and $470 \mathrm{~nm}$. The MLCT state of $(\mathbf{R u B})_{2}$ has a formally oxidized Ru-center and reduced dpp ligand, i.e. $\left[\mathrm{Ru}^{\mathrm{III}}(\mathrm{bpy})_{2}\left(\mathrm{dpp}^{-}\right) \mathrm{Ru}^{\mathrm{II}}(\mathrm{bpy})_{2}\right]^{4+}$, and summing the spectra of the electrochemically generated components (red line) well simulates the transient spectrum (solid gray line). Unfortunately, the spectrum of electrochemically reduced $\mathbf{R u B R h}$ cannot be used to simulate its MLCT or MMCT states (i.e. $\left[\mathrm{Ru}^{\mathrm{III}}(\mathrm{bpy})_{2}\left(\mathrm{dpp}^{-{ }^{-}}\right) \mathrm{Rh}^{\mathrm{III}} \mathrm{Cl}_{2}(\mathrm{bpy})_{2}\right]^{3+}$ or $\left[\mathrm{Ru}^{\mathrm{III}}(\mathrm{bpy})_{2}(\mathrm{dpp}) \mathrm{Rh}^{\mathrm{II}} \mathrm{Cl}_{2} \text { (phen) }\right]^{3+}$, respectively). This is because the reduction of $\mathbf{R u B R h}$ is irreversible due to chloride loss on the time scale of the spectroelectrochemistry experiment, and favors a square planar $\mathrm{Rh}(\mathrm{I})$ complex (i.e. $\left[\mathrm{Ru} \mathrm{u}^{\mathrm{II}}(\mathrm{bpy})_{2}(\mathrm{dpp}) \mathrm{Rh}^{\mathrm{I}}(\mathrm{phen})\right]^{3+}$ ) rather than a dpplocalized radical or $\mathrm{Rh}$ (II) $[2,36]$. The change in the transient spectra with time provides a clue, however. The spectra evolve during the first $10 \mathrm{ps}$ to resemble the spectrum of the oxidized complex, consistent with loss of a dpp-localized radical. Assuming that the formally reduced $\mathrm{Rh}$ (II) contributes little to the spectrum red of $350 \mathrm{~nm}$ for the MMCT state [37], the spectral evolution during the first $10 \mathrm{ps}$ is consistent with population conversion from the MLCT state to the MMCT state.

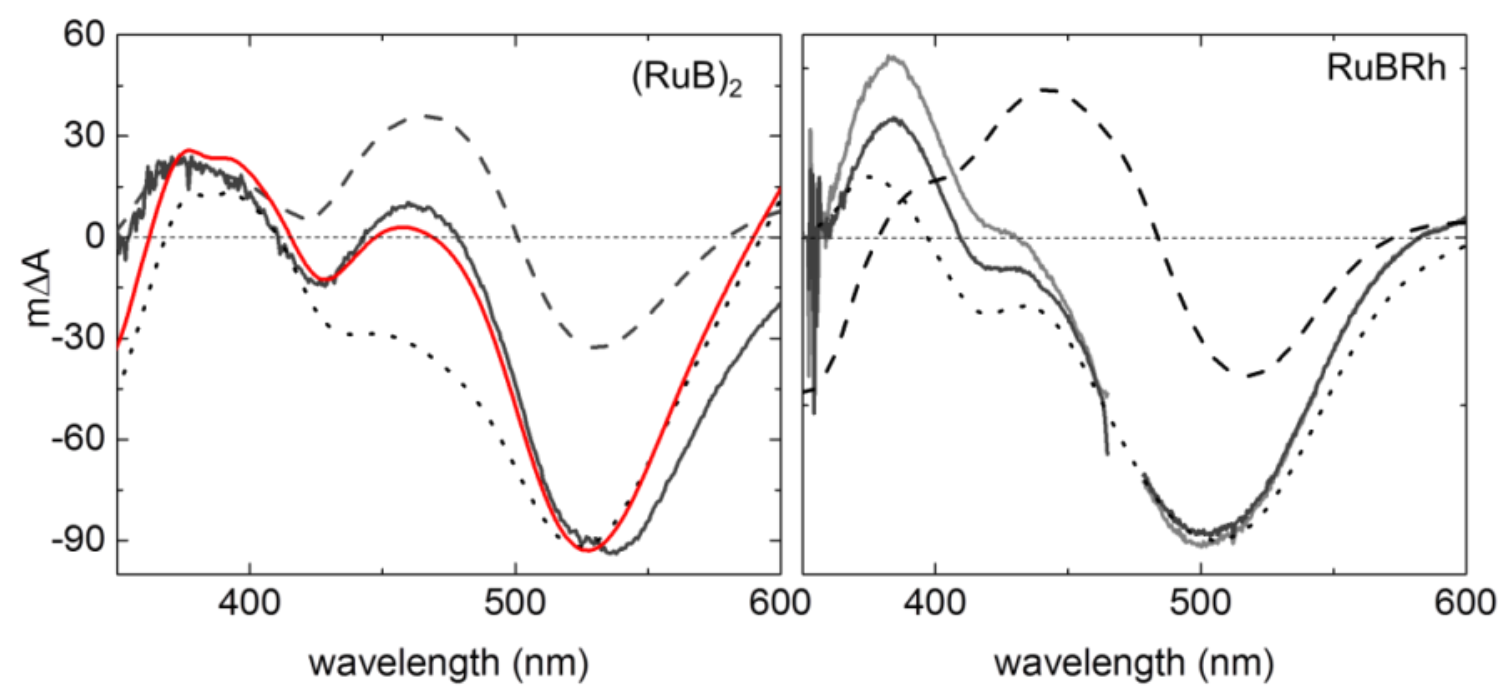

Fig. 3. Comparison of measured transient absorption spectra of $\left.\left[R u(b p y)_{2}\right)(d p p) R u(b p y)_{2}\right]^{4+}$ $\left((\mathbf{R u B})_{2}, \lambda_{\mathrm{ex}}=532 \mathrm{~nm}, t=10 \mathrm{~ns},-\right.$ ) $)$ and $\left[\mathrm{Ru}(\mathrm{bpy})_{2}(\mathrm{dpp}) \mathrm{RhCl}_{2}(\mathrm{phen})\right]^{3+}\left(\mathbf{R u B R h}, \boldsymbol{\lambda}_{\mathrm{ex}}=470 \mathrm{~nm}\right.$, $t=0.6 \mathrm{ps},-$ and $1200 \mathrm{ps},-$ ) to the spectra of electrochemically oxidized $(\cdots)$ or reduced complexes (---). Also shown are simluated TA spectra obtained by summing the oxidized and reduced spectra (-). $(\mathbf{R u B})_{2}$ was oxidized at $1.65 \mathrm{~V}$ versus $\mathrm{Ag} / \mathrm{AgCl}$ and reduced at $-1.3 \mathrm{~V}$. RuBRh was reduced at $-0.60 \mathrm{~V}$ and the oxidized spectrum is of the related bimetallic $\left[\mathrm{Ru}(\mathrm{bpy})_{2}(\mathrm{dpp}) \mathrm{RhCl}_{2}\left(\mathrm{~d}^{t} \mathrm{Bub}\right)\right]^{3+}$ at $1.85 \mathrm{~V}$. All spectra were from acetonitrile solutions. $\mathrm{d}^{t} \mathrm{Bub}$ is 4,4'-bis(tert-butyl)-2,2'-bipyridine. 
The other mixed-metal supramolecules show spectral features and evolution in the first $10 \mathrm{ps}$ similar to those of RuBRh, (Figs. 4, S2). The analog trimetallic complex with the LA-BL-ECBL-LA architecture, $(\mathbf{R u B})_{2} \mathbf{R h}$, has spectra in water or acetonitrile that are nearly coincident with RuBRh, highlighting the importance of the identity of the light absorber. The Oscontaining complexes $\mathbf{O s B R h}$, and $(\mathbf{O s B})_{2} \mathbf{R h}$ also show an absorptive feature near $380 \mathrm{~nm}$ and bleach centered in the visible region. Unlike RuBRh and $(\mathbf{R u B})_{2} \mathbf{R h}$, the weak absorptive feature red of $600 \mathrm{~nm}$ is not seen for $\mathbf{O s B R h}$, and $(\mathbf{O s B})_{2} \mathbf{R h}$ due to a coincident bleach of the more intense ${ }^{1} \mathrm{GS} \rightarrow{ }^{3} \mathrm{MLCT}$ transition of the Os complexes. The spectra of all evolve at early times in the near-UV region on timescales comparable to RuBRh (Tables 1 and 2) indicating that following excitation, these also rapidly relax to the ${ }^{3} \mathrm{MMCT}$ state. As will be seen below, this insensitivity of electron transfer rate is a result of the similar driving forces for all of the mixed metal complexes (Section 3.2).

Table 2. Kinetic data for $\left[\mathrm{Os}(\mathrm{bpy})_{2}(\mathrm{dpp}) \mathrm{Os}(\mathrm{bpy})_{2}\right]^{4+}$,

$\left[\mathrm{Os}(\mathrm{bpy})_{2}(\mathrm{dpp}) \mathrm{RhCl}_{2}(\mathrm{phen})\right]^{3+}$, and $\left[\left\{\mathrm{Os}(\mathrm{bpy})_{2}(\mathrm{dpp})\right\}_{2} \mathrm{RhCl}_{2}\right]^{5+a}$.

\begin{tabular}{lccccccc}
\hline Compound & Solvent $^{a}$ & $\lambda^{\mathrm{ex}}(\mathrm{nm})$ & $\lambda^{\mathrm{prb}}(\mathrm{nm})$ & $\mathrm{A}_{1}{ }^{b}$ & $\tau_{1}(\mathrm{ps})$ & $\mathrm{A}_{2}{ }^{b}$ & $\tau_{2}(\mathrm{ps})$ \\
\hline $\boldsymbol{( \mathbf { O s B } ) _ { 2 } { } ^ { c }}$ & $\mathrm{MeCN}$ & 512 & 560 & - & - & -1 & $\sim 1000$ \\
OsBRh & $\mathrm{H}_{2} \mathrm{O}$ & 470 & 384 & 0.15 & $4.6(1.3)$ & 0.49 & $476(28)$ \\
& & & 513 & -- & -- & -1 & $409(16)$ \\
$(\mathbf{O s B})_{2} \mathbf{R h}$ & $\mathrm{H}_{2} \mathrm{O}$ & 470 & 384 & 0.22 & $3.0(0.4)$ & 0.43 & $286(16)$ \\
& & & 543 & -- & - & -1 & $244(10)$
\end{tabular}

${ }^{a} \mathrm{dpp}=$ 2,3-bis(2-pyridyl)pyrazine, bpy $=2,2$ '-bipyridine, phen $=1,10$-phenanthroline, $\mathrm{MeCN}=$ acetonitrile

${ }^{b}$ Amplitudes are normalized to the sum of those contributing to decay of the MLCT bleach.

Error for each was \pm 0.01

${ }^{c}$ Ref. [4] 

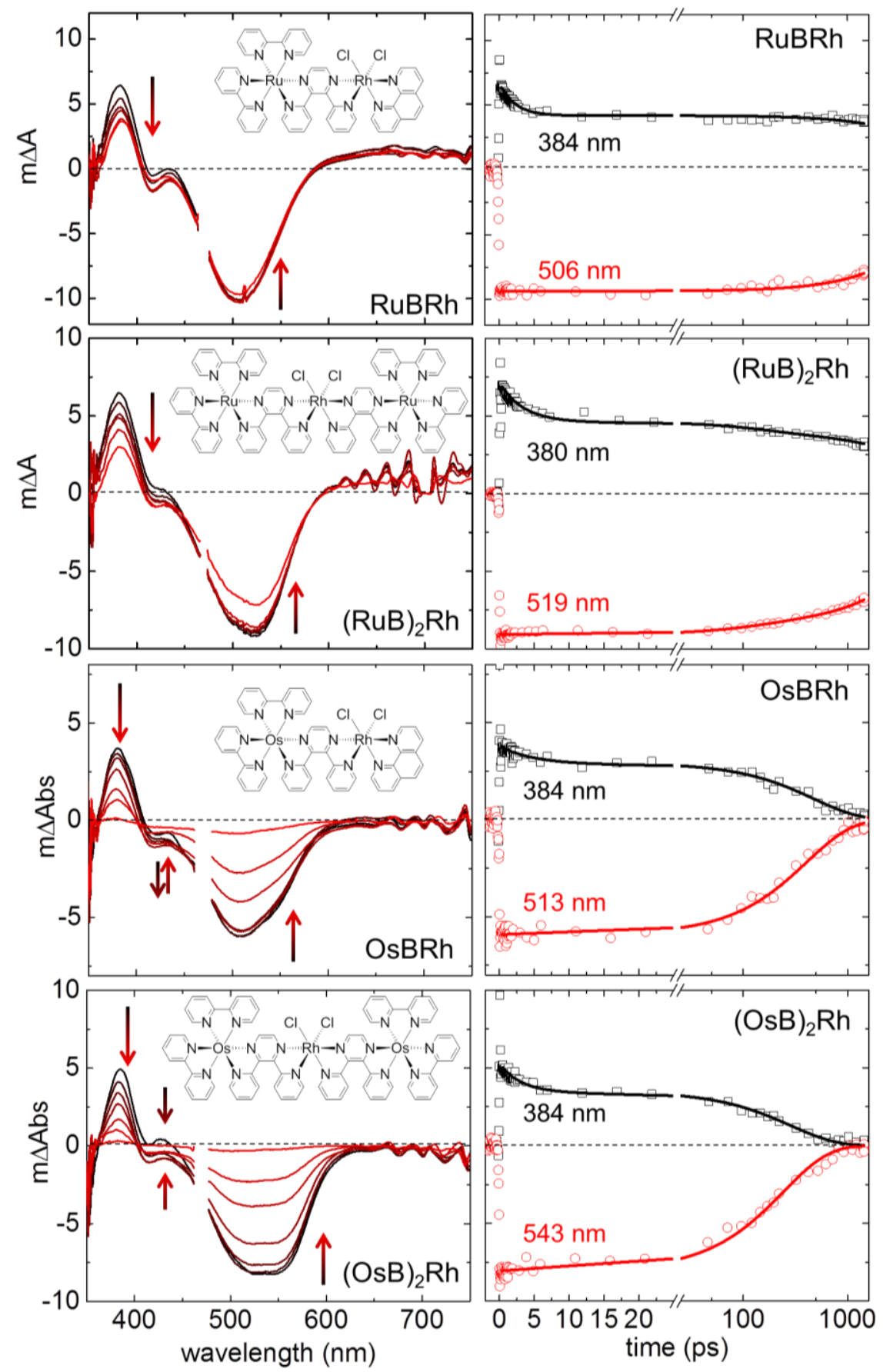

Fig. 4. (left) Transient absorption spectra of $\left[\mathrm{Ru}(\mathrm{bpy})_{2}(\mathrm{dpp}) \mathrm{RhCl}_{2}(\text { phen })\right]^{3+}$ (RuBRh), $\left[\left\{\mathrm{Ru}(\mathrm{bpy})_{2}(\mathrm{dpp})\right\}_{2} \mathrm{RhCl}_{2}\right]^{5+} \quad\left((\mathbf{R u B})_{2} \mathbf{R h}\right), \quad\left[\mathrm{Os}(\mathrm{bpy})_{2}(\mathrm{dpp}) \mathrm{RhCl}_{2}(\mathrm{phen})\right]^{3+} \quad(\mathbf{O s B R h}), \quad$ and $\left[\left\{\mathrm{Os}(\mathrm{bpy})_{2}(\mathrm{dpp})\right\}_{2} \mathrm{RhCl}_{2}\right]^{5+}\left((\mathbf{O s B})_{2} \mathbf{R h}\right)$ obtained in deaerated, room-temperature water, following $470 \mathrm{~nm}$ excitation (110 $\mathrm{nJ}, 150 \mu \mathrm{m}$ spot). The spectra of each (from black to red) were taken at $0.6,2,5,10,100$, and $1200 \mathrm{ps}$. (Ru) or at $0.4,3,7,48,190,336$, and $1000 \mathrm{ps}(\mathrm{Os})$. Decays of the maximal absorption ( $\square$ ) and minimal bleach ( $($ ) are plotted. Also shown are fits of the decays to exponential functions (lines). 
The complexes $(\mathbf{O s T})_{2} \mathbf{R h}$ and OsTRh demonstrate photochemistry attributable to an MMCT state [25,29], which suggests that the MLCT state of these complexes undergoes electron transfer like the bpy terminated complexes above. The dynamics are more difficult to interpret for $(\mathbf{O s T})_{2} \mathbf{R h}$ and OsTRh because of the overall faster return to the ground state $\left(t_{1 / 2} \approx 15 \mathrm{ps}\right)$, which is discussed in more detail below. Both the bleach and induced absorption decay with the same time constants, suggesting that the state populated within the instrument response time ( $200 \mathrm{fs}$ ) is the lowest energy state. Closer inspection of the near-UV feature (Fig. S4) shows that the spectra of both $(\mathbf{O s T})_{2} \mathbf{R h}$ and $\mathbf{O s T R h}$ shift to the blue due to faster relaxation of the red edge of the absorptive feature. The spectral shift could indicate that like the other mixed-metal supramolecules, an initially populated MLCT state is rapidly undergoing electron transfer to give the MMCT and the larger amplitude of the fast relaxation near $420 \mathrm{~nm}$ corresponds to the loss of the dpp-localized radical.
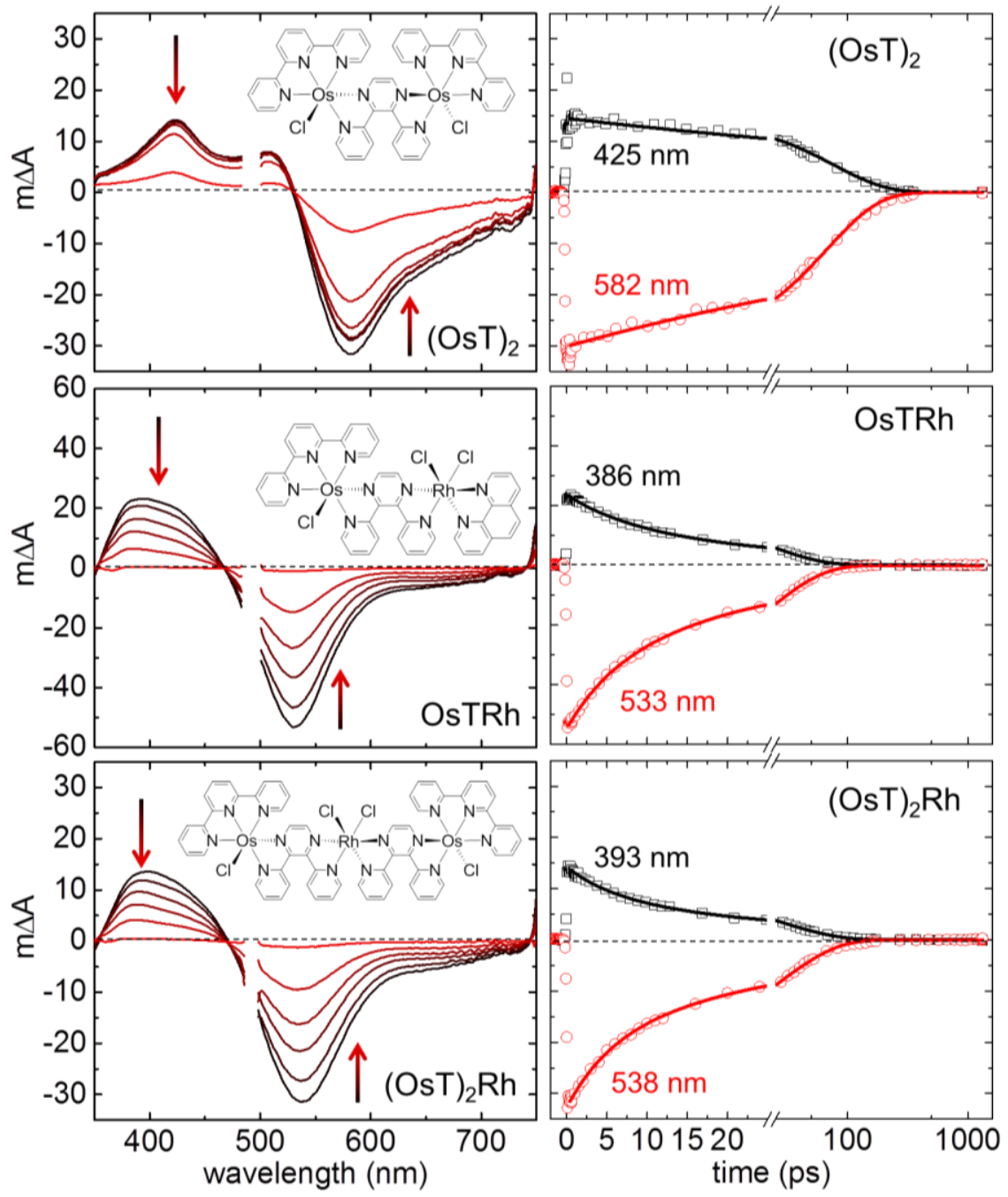

Fig. 5. (left) Transient absorption spectra of $\left[\mathrm{OsCl}(\text { tpy)(dpp)OsCl(tpy) }]^{2+} \quad\right.$ (top) $\left[\mathrm{OsCl}(\mathrm{tpy})(\mathrm{dpp}) \mathrm{RhCl}_{2}(\mathrm{phen})\right]^{2+}$ (middle), and $\left[\{\mathrm{OsCl}(\mathrm{tpy})(\mathrm{dpp})\}_{2} \mathrm{RhCl}_{2}\right]^{3+}$ (bottom) obtained in deaerated, room-temperature acetonitrile, following $490 \mathrm{~nm}$ excitation $(200 \mathrm{~nJ}, 150 \mu \mathrm{m}$ spot). The spectra of each (from black to red) were taken at 0.6, 2, 5, 10, 25, and 100 ps. (right) Decays of the maximal absorption ( $\square$ ) and minimal bleach ( $\circ$ ) are plotted. Also shown are fits to the decays to exponential functions (lines). 
Table 3. Kinetic data for $[\mathrm{OsCl}(\mathrm{tpy})(\mathrm{dpp}) \mathrm{OsCl}(\mathrm{tpy})]^{2+}$, $\left[\mathrm{OsCl}(\text { tpy })(\mathrm{dpp}) \mathrm{RhCl}_{2}(\mathrm{phen})\right]^{2+}$, and $\left[\{\mathrm{OsCl}(\mathrm{tpy})(\mathrm{dpp})\}_{2} \mathrm{RhCl}_{2}\right]^{3+a}$.

\begin{tabular}{|c|c|c|c|c|c|c|c|}
\hline Compound & Solvent ${ }^{a}$ & $\begin{array}{c}\lambda^{\mathrm{ex}} \\
(\mathrm{nm})\end{array}$ & $\begin{array}{c}\lambda^{\mathrm{prb}} \\
(\mathrm{nm})\end{array}$ & $\mathrm{A}_{1}^{b}$ & $\tau_{1}(\mathrm{ps})$ & $\mathrm{A}_{2}^{b}$ & $\tau_{2}(\mathrm{ps})$ \\
\hline \multirow[t]{2}{*}{$(\mathrm{OsT})_{2}$} & $\mathrm{MeCN}$ & 490 & 425 & -- & -- & 0.48 & $78(3)$ \\
\hline & & & 582 & -- & -- & -1 & $68(1)$ \\
\hline \multirow[t]{2}{*}{ OsTRh } & $\mathrm{MeCN}$ & 490 & 386 & 0.14 & $6.9(0.3)$ & 0.29 & $23(1)$ \\
\hline & & & 533 & -0.35 & $5.9(0.2)$ & -1 & $23(1)$ \\
\hline \multirow[t]{4}{*}{$(\mathrm{OsT})_{2} \mathrm{Rh}$} & $\mathrm{MeCN}$ & 490 & 393 & 0.19 & $6.3(0.3)$ & 0.25 & $30(1)$ \\
\hline & & & 538 & -0.40 & $5.5(0.2)$ & -0.60 & $30(1)$ \\
\hline & $\mathrm{H}_{2} \mathrm{O}$ & 470 & 389 & 0.26 & $2.8(0.1)$ & 0.43 & $32(1)$ \\
\hline & & & 524 & -0.34 & $3.6(0.2)$ & -0.66 & $33(1)$ \\
\hline
\end{tabular}

\footnotetext{
${ }^{a} \mathrm{dpp}=2,3$-bis(2-pyridyl)pyrazine, tpy $=2,2^{\prime}, 6^{\prime}, 2^{\prime \prime}$-terpyridine, phen $=1,10$-phenanthroline, $\mathrm{MeCN}=$ acetonitrile

${ }^{b}$ Amplitudes are normalized to the sum of those contributing to decay of the MLCT bleach. Error for each was \pm 0.01
}

Unlike the forward ET process, return to the ground state (i.e. back electron transfer) occurs on different timescales depending on the identity of the light absorber subunit. Returning to first consider RuBRh, by 100 ps after excitation, all spectral features decay at the same rate to give rise to isosbestic points at $410 \mathrm{~nm}$ and $570 \mathrm{~nm}$ (Fig. 2). The monotonic decay is slow, leading to only a $15 \%$ reduction in spectral features by $1.3 \mathrm{~ns}$, consistent with consistent with the earlier reported lifetimes in the 10-30 ns range [24,26,29]. The trimetallic analog, $(\mathbf{R u B})_{2} \mathbf{R h}$, relaxes on similar timescales, highlighting the importance of the light absorber on controlling the relaxation dynamics [38].

It is also important to note that relaxation of the mixed-metal complexes is markedly faster than their model complex analogs. Faster relaxation of $\mathbf{R u B R h}$ and $(\mathbf{R u B})_{\mathbf{2}} \mathbf{R h}$ compared to $(\mathbf{R u B})_{2}(\sim 125 \mathrm{~ns})$ has been interpreted as evidence for static electron transfer quenching by the attached $\mathrm{Rh}(\mathrm{III})$ [11], i.e.

$$
\tau_{R u R h}=\left(k_{E T}+1 / \tau_{R u R u}\right)^{-1}
$$

Eq. 2

where $\tau_{i}$ is the lifetime of mixed-metal $(R u R h)$ or model complex $(R u R u)$, and $k_{E T}$ is the electron transfer rate constant. Rather than a lifetime dominated by MLCT relaxation, however, our results point to relaxation by back electron transfer from the MMCT state. With OsBRh and $(\mathbf{O s B})_{2} \mathbf{R h}$, the lifetimes are considerably shorter than the Ru-containing homologs ( 450 ps and $\sim 250 \mathrm{ps})$, but also shorter than the (OsB) $)_{2}$ model ( $\left.\sim 1 \mathrm{~ns}\right)$. This trend continues with OsTRh and $(\mathbf{O s T})_{2} \mathbf{R h}$, where the lifetimes ( $\left.\sim 25 \mathrm{ps}\right)$ are significantly shorter than the model $(\mathbf{O s T})_{\mathbf{2}}(\sim 75 \mathrm{ps})$. The analysis using Eq. 2 suggests that $k_{E T}$ for OsTRh is $\sim 10^{3}$ times greater than for RuBRh. A much faster electron transfer rate implies that the driving force is much greater for ET in OsTRh and/or the donor-acceptor coupling matrix is also much larger, which is not borne out by the energetic analysis shown below.

\subsection{Survey of Mixed-Metal Energetics}

The forward and reverse electron transfer kinetics are each controlled by three main parameters: the driving force for electron transfer $\left(\Delta G_{E T}, \Delta G_{b E T}\right)$; the coupling matrix element 
between the bridging ligand localized radical donor and $\mathrm{Rh}(\mathrm{III})$ acceptor $\left(H_{L R h}\right)$, as well as the $\mathrm{Rh}(\mathrm{II})$ donor and $\mathrm{M}(\mathrm{III})$ acceptor, $\left(H_{R h M}\right)$; and by the reorganization energy associated with the electron transfer event $\left(\lambda_{E T}, \lambda_{b E T}\right)$. Empirical values for most of the parameters can be obtained from a Franck-Condon analysis of steady-state spectra and electrochemistry [29,31,35], Table 4.

Table 4. Comparison of the free-energy of a thermally equilibrated metal-to-ligand charge transfer state and the first reduction of each supramolecular complex ${ }^{a}$

\begin{tabular}{lcccccc}
\hline Compound & $\mathbf{E}_{\mathrm{o}}(\mathrm{eV})^{b}$ & $\Delta G_{\mathrm{ES}}^{\circ}(\mathrm{eV})^{c}$ & $E^{\circ}\left(\mathrm{M}^{\mathrm{III} / \mathrm{III}}\right)^{d, e}$ & $E_{\mathrm{ES}}^{\circ}(\mathrm{V})^{f}$ & $E_{p c / 2}(\mathrm{~V})^{d, g}$ & $\Delta G_{\mathrm{ET}}^{\circ}(\mathrm{eV})^{h}$ \\
\hline RuBRh & 1.81 & -2.00 & 1.65 & -0.32 & -0.36 & 0.03 \\
$(\mathbf{R u B})_{2} \mathbf{R h}$ & 1.77 & -1.96 & 1.60 & -0.33 & -0.34 & 0.00 \\
OsBRh & 1.45 & -1.64 & 1.24 & -0.37 & -0.39 & 0.01 \\
$(\mathbf{O s B})_{2} \mathbf{R h}$ & 1.43 & -1.62 & 1.21 & -0.38 & -0.34 & -0.04 \\
OsTRh & 1.28 & -1.47 & 0.83 & -0.61 & -0.52 & -0.09 \\
$(\mathbf{O s T})_{2} \mathbf{R h}$ & 1.24 & -1.43 & 0.85 & -0.55 & -0.46 & -0.09 \\
\hline
\end{tabular}

${ }^{a} \mathrm{MeCN}$ solvent, reduction potentials versus $\mathrm{Ag} / \mathrm{AgCl}\left(3 \mathrm{~m} \mathrm{NaCl}, 0.45 \pm 0.02 \mathrm{~V}\right.$ versus $\mathrm{Fc}^{+/ 0}$ in $\left.\mathrm{MeCN}\right)$.

Relationship between potential $(E)$ and free energy change $(\Delta G)$ is $\Delta G=-n F\left(E_{f}-E_{i}\right)$, where $n$ is number of charge units transferred and $F$ is Faraday's constant $1 \mathrm{eV} / \mathrm{V}$.

${ }^{b}$ Energy between the ground state and ${ }^{3} \mathrm{MLCT}$, as measured either from the photoluminescence spectrum or the wavelength at half height for the red edge of the ${ }^{3}$ MLCT absorption band $( \pm 0.02 \mathrm{eV})$.

${ }^{c} \Delta G_{E S}^{\circ}=\mathrm{E}_{\mathrm{o}}+\lambda_{\mathrm{ES}}, \lambda_{\mathrm{ES}}$ was estimated as $0.16 \mathrm{eV}$ based in values determined from emission spectral fitting of similar $\mathrm{Ru}(\mathrm{d} \pi) \rightarrow \mathrm{L}\left(\pi^{*}\right) \mathrm{CT}$ transitions $[31,35]$.

${ }^{d}$ From Ref [29].

${ }^{e} E^{\circ}\left(\mathrm{M}^{\mathrm{III} / \mathrm{II}}\right)=E_{1 / 2}=\left(E_{p c}+E_{p a}\right) / 2$, reduction potential at the $\mathrm{Os}{ }^{\mathrm{III} / \mathrm{II}}$ or $\mathrm{Ru}^{\mathrm{III} / \mathrm{II}}$ redox couple

${ }^{f} E^{\circ}{ }_{\mathrm{ES}}=E^{\circ}\left(\mathrm{M}^{\mathrm{III} / \mathrm{II}}\right)+\Delta G_{E S}^{\circ} / F$

${ }^{g}$ Irreversible reduction corresponding to ECEC mechanism for the $\mathrm{Rh}^{\mathrm{III} / \mathrm{II} / \mathrm{I}}$ redox couple, cathodic peak potential given for $v=100 \mathrm{mV} / \mathrm{s}$. Potential at half cathodic peak height, $E_{p c / 2} \approx 0.05 \mathrm{~V}+E_{p c}$.

${ }^{h}$ Estimate of the free energy for MLCT $\rightarrow \mathrm{MMCT}$ transfer, where $\Delta G_{\mathrm{ET}}^{\circ}=-F\left(E_{p c / 2}-E_{\mathrm{ES}}^{\circ}\right)$.

The free energy of the excited state $\left(\Delta G_{E S}^{\circ}\right)$ is calculated from either the photoluminescence spectrum (RuBRh and $\left.(\mathbf{R u B})_{\mathbf{2}} \mathbf{R h}\right)$ or the ${ }^{1} \mathrm{GS} \rightarrow{ }^{3} \mathrm{MLCT}$ absorption band $\left(\mathbf{O s B R h},(\mathbf{O s B})_{2} \mathbf{R h}\right.$, OsTRh and $\left.(\mathbf{O s T})_{2} \mathbf{R h}\right)$. The standard reduction potential of the light absorber metal center, $E^{\circ}\left(\mathrm{M}^{\mathrm{III} / \mathrm{II}}\right)$, is from the $E_{1 / 2}$ reported for the $\mathrm{Ru}^{\mathrm{III} / \mathrm{II}}$ or $\mathrm{Os}{ }^{\mathrm{III} / \mathrm{II}}$ redox couple versus $\mathrm{Ag} / \mathrm{AgCl}$. This allows us to calculate the reduction potential for the excited state couple ${ }^{3} \mathrm{MLCT} / \mathrm{M}$ (III) from free energy difference, i.e. $E_{\mathrm{ES}}^{\circ}=E^{\circ}\left(\mathrm{M}^{\mathrm{III} / \mathrm{II}}\right)+\Delta G_{E S}^{\circ} / F$, where $F$ is Faraday's constant $(1 \mathrm{eV} / \mathrm{V})$. The driving force for the forward electron transfer reaction is the difference in energy of the ${ }^{3}$ MLCT oxidation and $\mathrm{Rh}(\mathrm{III})$ reduction. The reduction potential for the $\mathrm{Rh}^{\mathrm{II} / \mathrm{II}}$ couple, $E^{\circ}\left(\mathrm{Rh}^{\mathrm{III} / I I}\right)$, however cannot be determined experimentally because the reduction is quickly followed by a chemical step, making the electrochemistry irreversible. A good relative measure of the $\mathrm{Rh}$ reduction can be made comparing the potential at half the cathodic peak height $\left(E_{p c / 2} \approx\right.$ $0.05 \mathrm{~V}+E_{p c}$ ) for each complex based on the observation that the slope of the cathodic wave for the $\mathrm{Rh}$ reduction is the same for each. Using this value, the ${ }^{3} \mathrm{MLCT} \rightarrow{ }^{3} \mathrm{MMCT}$ driving force $\left(\Delta G_{E T}^{\circ}\right.$ ) for each mixed-metal complex is calculated from the difference between the ${ }^{3}$ MLCT state and Rh-center reduction potentials, i.e. $\Delta G_{E T}^{\circ}=-F\left(E_{p c / 2}-E_{E S}^{\circ}\right)$. The free-energy change going from the ${ }^{3} \mathrm{MMCT}$ state to the ${ }^{1} \mathrm{GS}\left(\Delta G^{\circ}{ }_{b E T}\right)$ is estimated as the free energy difference $\Delta G_{E S}^{\circ}-\Delta G_{E T}^{\circ}$. The results of energetic analysis for all six mixed-metal supramolecules are presented in Table 4. 
Reorganization energies and coupling constants are estimated from analysis of literature values reported for monometallic model complexes. Displacement along the ${ }^{1} \mathrm{GS} \rightarrow{ }^{3} \mathrm{MLCT}$ (ML) and ${ }^{3} \mathrm{MLCT} \rightarrow{ }^{3} \mathrm{MMCT}$ (ET) reaction coordinates can be approximated as orthogonal distortions predominantly around the $\mathrm{Ru}$ - or Os-center for the first step and Rh-center for the second. Solvent reorganization energies for both of these are expected to be modest $\left(\lambda_{\mathrm{o}, \mathrm{ML}} \approx \lambda_{\mathrm{o}, \mathrm{ET}} \approx 0.3\right.$ $\mathrm{eV}$ ) given the short intramolecular donor-acceptor distances involved in each charge transfer step compared to the large sizes of the molecules [39,40]. Inner-sphere reorganization $\left(\lambda_{i}\right)$ is estimated to be smaller for the ${ }^{1} \mathrm{GS} \rightarrow{ }^{3}$ MLCT transition $\left(\lambda_{i, \mathrm{ML}} \approx 0.2 \mathrm{eV}\right)$ due to the small distortions accompanying either $\mathrm{M}\left(\mathrm{d} \pi^{6}\right) \rightarrow \mathrm{M}\left(\mathrm{d} \pi^{5}\right)$ or $\mathrm{dpp}\left(\pi^{*^{0}}\right) \rightarrow \mathrm{dpp}\left(\pi^{*^{1}}\right)$ transitions [41,42]. The ${ }^{3}$ MLCT $\rightarrow{ }^{3}$ MMCT transition corresponds to a $\mathrm{Rh}\left(\mathrm{d} \pi^{6}\right) \rightarrow \mathrm{Rh}\left(\mathrm{d} \pi^{6} \mathrm{~d} \sigma^{*^{1}}\right)$ change in electronic configuration, which contributes a large Jahn-Teller distortion around the Rh-center and for which $\lambda_{i, \mathrm{ET}}$ is $\sim 0.9 \mathrm{eV}$ (based on $\mathrm{Rh}^{\mathrm{III}}$-centered ${ }^{3} \mathrm{LF}$ transitions $[43,44]$ ). The total reorganization energy following return to the ground state, ${ }^{3} \mathrm{MMCT} \rightarrow{ }^{1} \mathrm{GS}(\mathrm{bET})$, is approximated as the vector sum of $\lambda_{\mathrm{ET}}$ and $\lambda_{\mathrm{ML}}$, i.e.

$$
\lambda_{\mathrm{bET}}=\left[\left(\lambda_{i, \mathrm{ML}}+\lambda_{o, \mathrm{ML}}\right)^{2}+\left(\lambda_{i, \mathrm{ET}}+\lambda_{o, \mathrm{ET}}\right)^{2}\right]^{1 / 2} \quad \text { Eq. } 3,
$$

and using the values above, $\lambda_{\mathrm{bET}}$ is $\sim 1.3 \mathrm{eV}$. Based on the low estimated driving force for ${ }^{3} \mathrm{MLCT} \rightarrow{ }^{3} \mathrm{MMCT}\left(\Delta G^{\circ} \mathrm{ET}\right.$, Table 4$)$, the thermal barrier for the forward electron transfer is approximated as $\Delta G^{\ddagger} \approx \lambda_{\mathrm{ET}} / 4-H_{\mathrm{LRh}}$, where $\lambda_{\mathrm{ET}}$ is the sum of inner- and outer-sphere reorganization energies and $H_{\mathrm{LRh}}$ is the coupling matrix element for the $\operatorname{dpp}\left(\pi^{*}\right)$ donor and $\mathrm{Rh}\left(\mathrm{d} \sigma^{*}\right)$ acceptor. Analyses from other ligand-bridged complexes provide a reasonable range for $H_{\mathrm{LRh}}$ between 0.05 and $0.2 \mathrm{eV}[39,45]$. Therefore $\Delta G^{\ddagger}$ is estimated to be similar to $k_{B} T$ at room temperature $\left(0.05\right.$ to $\left.0.2 \mathrm{eV}, k_{B} T=0.026 \mathrm{eV}\right)$. A semi-quantitative state diagram is presented for RuBRh in Fig. 6 using the calculated state energies and estimated reorganization energies and coupling constants. The apparent difference in force constants associated with the ${ }^{1} \mathrm{GS}$ and ${ }^{3} \mathrm{MLCT}$ or ${ }^{3} \mathrm{MMCT}$ surfaces is a consequence of representing localized displacements associated with each excited state on a simplified one-dimensional nuclear coordinate. This picture is analogous to the Jablonski diagram depicted in Fig. 1. 


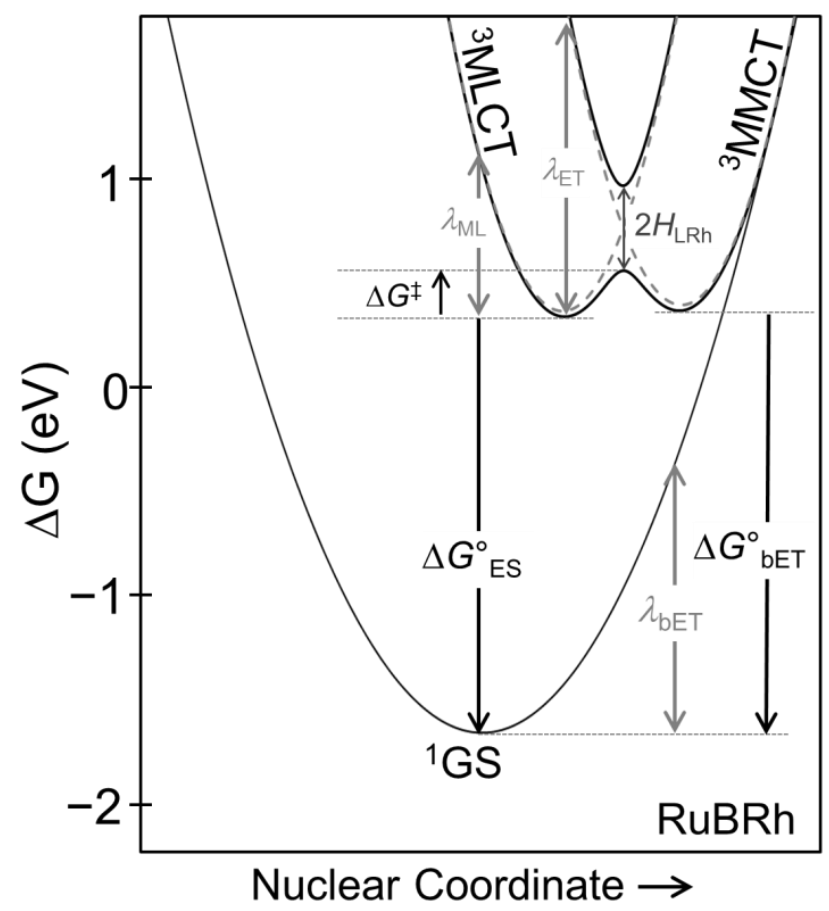

Fig. 6. Semi-quantitative free-energy diagram illustrating the state alignment of $\mathbf{R u B R h}\left(\Delta G^{\circ}{ }_{\mathrm{bET}}\right.$ $=-2.0 \mathrm{eV})\left(\Delta G_{\mathrm{bET}}^{\circ}\right.$ is the free energy difference between the triplet metal-to-metal charge transfer state $\left({ }^{3} \mathrm{MMCT}\right)$ and singlet ground state $\left.\left({ }^{1} \mathrm{GS}\right)\right)$. The states are represented as parabolic surfaces and energies are relative to the $\mathrm{Ag} / \mathrm{AgCl}$ half-cell potential $\left(\Delta G=-F\left(E-E_{\mathrm{Ag}}\right)\right.$ where $F$ is $\left.1 \mathrm{eV} / \mathrm{V}, E^{\circ}(\mathrm{Ag} / \mathrm{AgCl})=E^{\circ}(\mathrm{NHE})+0.226 \mathrm{~V}\right)$. The nuclear coordinate combines inner-sphere and outer-sphere reorganization $(\lambda)$. The difference in parabolic force constants between the ${ }^{3} \mathrm{MLCT}$ and ${ }^{3} \mathrm{MMCT}$ surfaces compared to the ${ }^{1} \mathrm{GS}$ is a consequence of representing localized nuclear distortions for each excited state on a simplified one-dimensional nuclear coordinate. The parameters used for reorganization are $\lambda_{\mathrm{ML}}=0.5 \mathrm{eV}, \lambda_{\mathrm{ET}}=1.2 \mathrm{eV}, \lambda_{\mathrm{bET}}=1.3 \mathrm{eV}$, and for coupling $H_{\mathrm{LRh}}=0.2 \mathrm{eV}$; where ML refers to ${ }^{1} \mathrm{GS} \rightarrow{ }^{3} \mathrm{MLCT}$, ET is ${ }^{3} \mathrm{MLCT} \rightarrow{ }^{3} \mathrm{MMCT}$, and bET is ${ }^{3} \mathrm{MMCT} \rightarrow{ }^{1} \mathrm{GS}$. MLCT refers to the metal-to-ligand charge transfer state.

\subsection{Model for Excited State Evolution and Decay}

Both forward electron transfer to generate a ${ }^{3} \mathrm{MMCT}$ state and the return to the ground state can be understood using a semi-quantitative model created using the analysis in Section 3.2. The driving force for transferring an electron from a pyrazine localized orbital on the reduced dpp to a $\mathrm{Rh}\left(\mathrm{d} \sigma^{*}\right)$ acceptor $\left({ }^{3} \mathrm{MLCT} \rightarrow{ }^{3} \mathrm{MMCT}\right)$ is expected to be small for each of the complexes studied (Table $4, \Delta G^{\circ}{ }_{\mathrm{ET}} \approx \pm 0.05 \mathrm{eV}$ ). The structural similarity between complexes also suggests that parameters such as reorganization energy and vibrational coupling between the dpp ${ }^{-{ }^{-}}$donor and $\mathrm{Rh}(\mathrm{III})$ acceptor will be nearly equal for all instances of ${ }^{3} \mathrm{MLCT} \rightarrow{ }^{3} \mathrm{MMCT}$. A kinetic analysis using Eq. 2 and comparing the decay constants with the appropriate model complex, however, implies $k_{E T}$ varies from $(40 \mathrm{ps})^{-1}$ for OsTRh and $(800 \mathrm{ps})^{-1}$ for OsBRh, to as slow as $(40 \mathrm{~ns})^{-1}$ for RuBRh. A large range of electron transfer rate constants seems unlikely in the context of the relative energetics of these complexes. Rather, our observation of a 3-7 ps time constant shared among the group suggests this time constant corresponds to formation of the ${ }^{3} \mathrm{MMCT}$ where the driving force has little dependence on the nature of the ${ }^{3}$ MLCT donor. The 
kinetics indicate that the ${ }^{3} \mathrm{MMCT}$ state is populated fast, consistent with electron transfer kinetics observed for strongly coupled systems $[5,6,46]$.

The range of time constants associated with return to the ground state can be explained by the relative free energy difference for ${ }^{3} \mathrm{MMCT} \rightarrow{ }^{1} \mathrm{GS}$ between the mixed-metal systems $\left(\Delta G^{\circ}{ }_{\text {bET }}\right)$. Using electrochemical and spectral fitting data (Table 4$), \Delta G^{\circ}{ }_{\text {bET }}$ is estimated to be $-2.0 \mathrm{eV}$ for $(\mathbf{R u B})_{2} \mathbf{R h}$ and $\mathbf{R u B R h},-1.6 \mathrm{eV}$ for $(\mathbf{O s B})_{2} \mathbf{R h}$ and $\mathbf{O s B R h}$, and $-1.3 \mathrm{eV}$ for (OsT) $)_{2} \mathbf{R h}$ and OsTRh. The rate of back electron transfer $\left(k_{b E T}\right)$ is proportional to $\exp \left[-\left(\lambda_{\mathrm{bET}}\right.\right.$ $\left.\left.+\Delta G^{\circ}{ }_{\mathrm{bET}}\right)^{2} / 4 \lambda_{\mathrm{bET}} k_{B} T\right]$, where $\lambda_{\mathrm{bET}}$ is the reorganization energy for transfer of an electron from $\operatorname{Rh}^{\mathrm{II}}\left(\mathrm{d} \pi^{6} \mathrm{~d} \sigma^{* 1}\right)$ to $\mathrm{M}^{\mathrm{III}}\left(\mathrm{d} \pi^{5}\right)$, and where the fastest rate occurs for values of $\Delta G^{\circ}{ }_{\text {bET }}$ approximately equal to $-\lambda_{\text {bET }}$. An estimated $\lambda_{\text {bET }}$ of $\sim 1.3 \mathrm{eV}$ suggests that for $(\mathbf{O s T})_{2} \mathbf{R h}$ and OsTRh the ${ }^{1} \mathrm{GS}$ surface crosses near the bottom of the ${ }^{3} \mathrm{MMCT}$ (Fig. 7, right), consistent with observation of ${ }^{3} \mathrm{MMCT} \rightarrow{ }^{1} \mathrm{GS}$ on the timescale of vibrational relaxation $\left(\tau_{\mathrm{vc}} \approx 15\right.$ ps according to $\left.[5,40,47]\right)$. Back electron transfer for $\mathbf{R u B R h}$ and $(\mathbf{R u B})_{2} \mathbf{R h}$ is in the Marcus-inverted region, leading to slower return to the ${ }^{1} \mathrm{GS}$. Although the number of mixed-metal systems included in this study is small, expanding the set of supramolecular complexes to those with a more systematic tuning of light absorber energetics may give additional insight into the back electron transfer process [35].

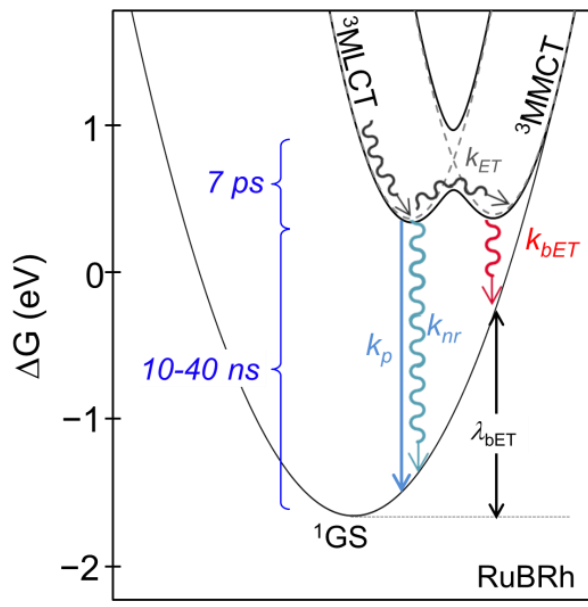

Nuclear Coordinate $\rightarrow$

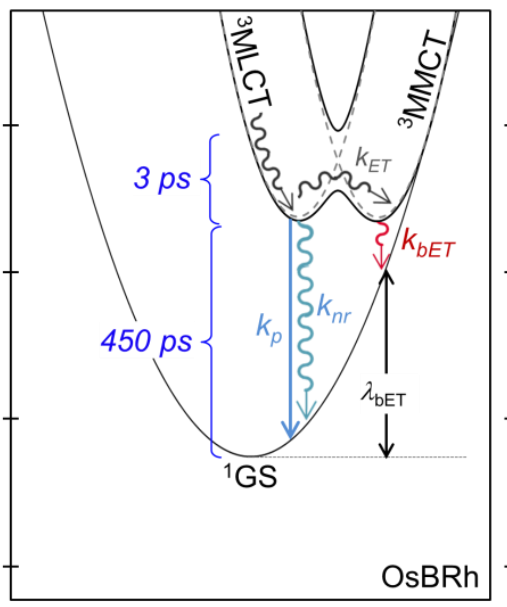

Nuclear Coordinate $\rightarrow$

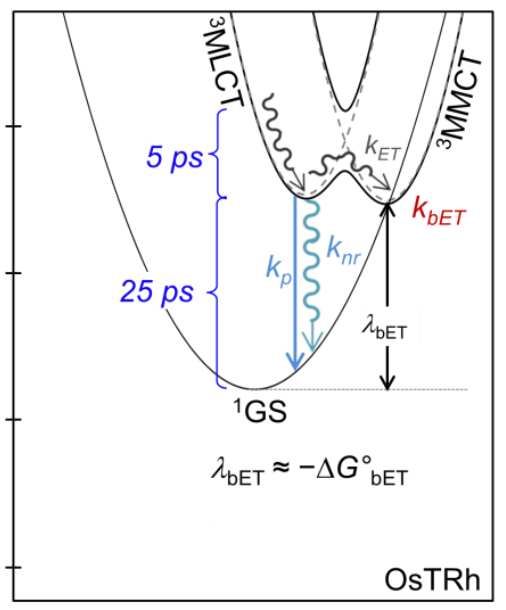

Nuclear Coordinate $\rightarrow$

Fig. 7. Semi-quantitative free-energy diagram illustrating the state alignment of (left to right) RuBRh $\left(\Delta G_{\text {bET }}^{\circ}=-2.0 \mathrm{eV}\right)$, OsBRh $\left(\Delta G^{\circ}{ }_{\mathrm{bET}}=-1.6 \mathrm{eV}\right)$, and OsTRh $\left(\Delta G^{\circ}{ }_{\mathrm{bET}}=-1.3 \mathrm{eV}\right)$ $\left(\Delta G^{\circ}{ }_{\text {bET }}\right.$ is the free energy difference between the triplet metal-to-metal charge transfer state $\left({ }^{3} \mathrm{MMCT}\right)$ and singlet ground state $\left.\left({ }^{1} \mathrm{GS}\right)\right)$. The states are represented as parabolic surfaces and energies are relative to the $\mathrm{Ag} / \mathrm{AgCl}$ half-cell potential $\left(\Delta G=-F\left(E-E_{\mathrm{Ag}}\right)\right.$ where $F$ is $\left.1 \mathrm{eV} / \mathrm{V}\right)$. The nuclear coordinate combines inner-sphere and outer-sphere reorganization $(\lambda)$. The parameters used for reorganization are $\lambda_{\mathrm{ML}}=0.5 \mathrm{eV}, \lambda_{\mathrm{ET}}=1.2 \mathrm{eV}, \lambda_{\mathrm{bET}}=1.3 \mathrm{eV}$, and for coupling $H_{\mathrm{LRh}}=0.2 \mathrm{eV}$; where ML refers to ${ }^{1} \mathrm{GS} \rightarrow{ }^{3} \mathrm{MLCT}$, ET is ${ }^{3} \mathrm{MLCT} \rightarrow{ }^{3} \mathrm{MMCT}$, and bET is ${ }^{3} \mathrm{MMCT} \rightarrow{ }^{1} \mathrm{GS}$. MLCT refers to the metal-to-ligand charge transfer state. Dynamical phenomena are represent by single headed arrows and labeled with a rate constant, where $k_{p}$ is phosphorescence, $k_{n r}$ is non-radiative relaxation from the MLCT state.

\section{Conclusion}

The photophysics, studied using femtosecond transient absorption spectroscopy, are presented for a series of mixed-metal polypyridyl supramolecules $\left(\mathrm{Ru}^{\mathrm{II}} \mathrm{Rh}^{\mathrm{III}}, \mathrm{Os}{ }^{\mathrm{II}} \mathrm{Rh}{ }^{\mathrm{III}}\right)$. We have 
observed spectroscopic evidence consistent with the formation of metal-to-metal charge transfer states (MMCT) following visible excitation of a metal-to-ligand charge transfer transition (MLCT) on times faster than $10 \mathrm{ps,} \mathrm{regardless} \mathrm{of} \mathrm{light} \mathrm{absorbing} \mathrm{subunit.} \mathrm{The} \mathrm{generally} \mathrm{faster}$ return to ground state of photoexcited mixed-metal supramolecules compared to model complexes (for which a charge separated MMCT state is inaccessible) cannot be explained by slow kinetics governed by parallel relaxation of the MLCT state and population of the MMCT state. Rather, our observations are in line with an explanation in which the distortion that accompanies population of the MMCT state provides a path for faster recovery of the ground state compared to supramolecular models without the $\mathrm{Rh}(\mathrm{III})$ center.

\section{Acknowledgements}

This material is based upon work solely supported as part of the UNC EFRC: Center for Solar Fuels, an Energy Frontier Research Center funded by the U.S. Department of Energy, Office of Science, Office of Basic Energy Sciences under Award Number DE-SC0001011. DFZ acknowledges Prof. Russ Schmehl (Tulane) for excellent discussions and early investigations using nanosecond transient absorption in his lab.

\section{References}

[1] G.F. Manbeck, K.J. Brewer, Photoinitiated electron collection in polyazine chromophores coupled to water reduction catalysts for solar $\mathrm{H}_{2}$ production, Coord. Chem. Rev., 257 (2013) 1660-1675.

[2] M. Elvington, K.J. Brewer, Photoinitiated electron collection at a metal in a rhodium centered mixedmetal supramolecular complex, Inorg. Chem., 45 (2006) 5242-5244.

[3] V. Balzani, A. Credi, M. Venturi, Photochemical Conversion of Solar Energy, ChemSusChem, 1 (2008) 26-58.

[4] H.B. Baudin, J. Davidsson, S. Serroni, A. Juris, V. Balzani, S. Campagna, L. Hammarström, Ultrafast Energy Transfer in Binuclear Ruthenium-Osmium Complexes as Models for Light-harvesting Antennas, J. Phys. Chem. A, 106 (2002) 4312-4319.

[5] S.E. Canton, K.S. Kjær, G. Vankó, T.B. van Driel, S.-i. Adachi, A. Bordage, C. Bressler, P. Chabera, M. Christensen, A.O. Dohn, A. Galler, W. Gawelda, D. Gosztola, K. Haldrup, T. Harlang, Y. Liu, K.B. Møller, Z. Németh, S. Nozawa, M. Pápai, T. Sato, T. Sato, K. Suarez-Alcantara, T. Togashi, K. Tono, J. Uhling, D.A. Vithanage, K. Wärnmark, M. Yabashi, J. Zhang, V. Sundström, M.M. Nielsen, Visualizing the non-equilibrium dynamics of photoinduced intramolecular electron transfer with femtosecond X-ray pulses, Nature Commun., 6 (2015) 7359(7351-7310).

[6] S.E. Canton, X. Zhang, J. Zhang, T.B. van Driel, K.S. Kjaer, K. Haldrup, P. Chabera, T. Harlang, K. Suarez-Alcantara, Y. Liu, J. Pérez, A. Bordage, M. Pápai, G. Vankó, G. Jennings, C.A. Kurtz, M. 
Rovezzi, P. Glatzel, G. Smolentsev, J. Uhlig, A.O. Dohn, M. Christensen, A. Galler, W. Gawelda, C. Bressler, H.T. Lemke, K.B. Møller, M.M. Nielsen, R. Lomoth, K. Wärnmark, V. Sundström, Toward Highlighting the Ultrafast Electron Transfer Dynamics at the Optically Dark Sites of Photocatalysts, J. Phys. Chem. Lett., 4 (2013) 1972-1976.

[7] C.P. Kubiak, Inorganic Electron Transfer: Sharpening a Fuzzy Border in Mixed Valency and Extending Mixed Valency across Supramolecular Systems, Inorg. Chem., 52 (2013) 5663-5676.

[8] M. Natali, S. Campagna, F. Scandola, Photoinduced electron transfer across molecular bridges: electron- and hole-transfer superexchange pathways, Chem. Soc. Rev., 43 (2014) 4005-4018.

[9] S.M. Arachchige, J.R. Brown, E. Chang, A. Jain, D.F. Zigler, K. Rangan, K.J. Brewer, Design Considerations for a System for Photocatalytic Hydrogen Production from Water Employing MixedMetal Photochemical Molecular Devices for Photoinitiated Electron Collection, Inorg. Chem., 48 (2009) 1989-2000.

[10] T.A. White, B.N. Whitaker, K.J. Brewer, Discovering the Balance of Steric and Electronic Factors Needed To Provide a New Structural Motif for Photocatalytic Hydrogen Production from Water, J. Am. Soc. Chem., 133 (2011) 15332-15334.

[11] S. Swavey, K.J. Brewer, Synthesis and study of $\mathrm{Ru}, \mathrm{Rh}, \mathrm{Ru}$ Triads: Modulation of orbital energies in a supramolecular architecture, Inorg. Chem., 41 (2002) 4044-4050.

[12] T.A. White, H.E. Mallalieu, J. Wang, K.J. Brewer, Mechanistic Insight into the Electronic Influences Imposed by Substituent Variation in Polyazine-Bridged Ruthenium(II)/Rhodium(III) Supramolecules, Chem. Euro. J., 20 (2014) 8265-8268.

[13] M. Elvington, J.R. Brown, S.M. Arachchige, K.J. Brewer, Photocatalytic hydrogen production from water employing a $\mathrm{Ru}, \mathrm{Rh}, \mathrm{Ru}$ molecular device for photointiated electron collection, J. Am. Chem. Soc., 129 (2007) 10644-10645.

[14] S.M. Arachchige, J.R. Brown, K.J. Brewer, Photochemical hydrogen production from water using the new photocatalyst $\left[\left\{(\text { bpy })_{2} \mathrm{Ru}(\mathrm{dpp})\right\}_{2} \mathrm{RhBr}_{2}\right]\left(\mathrm{PF}_{6}\right)_{5}$, J. Photochem. Photobiol. A, 197 (2008) 13-17.

[15] T. Stoll, M. Gennari, J. Fortage, C.E. Castillo, M. Rebarz, M. Sliwa, O. Poizat, F. Odobel, A. Deronzier, M.-N. Collomb, An Efficient $\mathrm{Ru}^{\mathrm{II}}-\mathrm{Rh}^{\mathrm{III}}-\mathrm{Ru}^{\mathrm{II}}$ Polypyridyl Photocatalyst for Visible-LightDriven Hydrogen Production in Aqueous Solution, Angew. Chem. Int. Ed., 53 (2014) 1654-1658.

[16] T.R. Canterbury, S.M. Arachchige, R.B. Moore, K.J. Brewer, Increased Water Reduction Efficiency of Polyelectrolyte-Bound Trimetallic [Ru, Rh, Ru] Photocatalysts in Air-Saturated Aqueous Solutions, Angew. Chem. Int. Ed., 54 (2015) 12819-12822.

[17] H.M. Rogers, T.A. White, B.N. Stone, S.M. Arachchige, K.J. Brewer, Nonchromophoric Halide Ligand Variation in Polyazine-Bridged Ru(II),Rh(III) Bimetallic Supramolecules Offering New Insight into Photocatalytic Hydrogen Production from Water, Inorg. Chem., 54 (2015) 3545-3551.

[18] R. Zhou, B. Sedai, G.F. Manbeck, K.J. Brewer, New Supramolecular Structural Motif Coupling a Ruthenium(II) Polyazine Light Absorber to a Rhodium(I) Center, Inorg. Chem., 52 (2013) 13314-13324. 
[19] H.M. Rogers, S.M. Arachchige, K.J. Brewer, Enhancement of Solar Fuel Production Schemes by Using a Ru,Rh,Ru Supramolecular Photocatalyst Containing Hydroxide Labile Ligands, Chem. Euro. J., 21 (2015) 16948-16954.

[20] S.M. Molnar, G.E. Jensen, L.M. Volger, S.W. Jones, L. Laverman, J.S. Bridgewater, M.M. Richter, K.J. Brewer, Photochemical Properties of mixed-metal Supramolecular Complexes, J. Photochem. Photobiol. A, 80 (1994) 315-322.

[21] K. Kalyanasundaram, M. Graetzel, M.K. Nazeeruddin, Excited-state interactions in ligand-bridged chromophore-quencher complexes containing rhodium(III) and ruthenium(II) polypyridyl units, J. Phys. Chem., 96 (1992) 5865-5872.

[22] M.T. Indelli, F. Scandola, J.-P. Collin, J.-P. Sauvage, A. Sour, Photoinduced Electron and Energy Transfer in Rigidly Bridged Ru(II)-Rh(III) Binuclear Complexes, Inorg. Chem., 35 (1996) 303-312.

[23] C.J. Kleverlaan, M.T. Indelli, C.A. Bignozzi, L. Pavanin, F. Scandola, G.M. Hasselman, G.J. Meyer, Stepwise Charge Separation in Heterotriads. Binuclear $\mathrm{Ru}(\mathrm{II})-\mathrm{Rh}(\mathrm{III})$ Complexes on Nanocrystalline Titanium Dioxide, J. Am. Soc. Chem., 122 (2000) 2840-2849.

[24] D.F. Zigler, J. Wang, K.J. Brewer, Ruthenium(II)-polyazine light absorbers bridged to reactive cisdichlororhodium(III) centers in a bimetallic molecular architecture, Inorg. Chem., 47 (2008) 1134211350.

[25] J. Wang, The Design, Synthesis and Study of Mixed-Metal Ru,Rh and Os,Rh Complexes with Biologically Relevant Reactivity, Chemistry, Virginia Polytechnic Institute and State University, Blacksburg, VA, 2013.

[26] T.A. White, Design and Modification of Polyazine-Bridged Ru(II), Rh(III) Bimetallic and Trimetallic Supramolecular Complexes Applicable in Solar Energy Harvesting for the Photocatalytic Reduction of Water to Hydrogen, Chemistry, Virginia Polytechnic Institute and State University, Blacksburg, VA, 2013.

[27] D.F. Zigler, M.T. Mongelli, M. Jeletic, K.J. Brewer, A trimetallic supramolecular complex of osmium(II) and rhodium(III) displaying MLCT transitions in the near-IR, Inorg. Chem. Commun., 10 (2007) 295-298.

[28] M.M. Richter, K.J. Brewer, Investigation of the spectroscopic, electrochemical, and spectroelectrochemical properties of osmium(II) complexes incorporating polyazine bridging ligands: formation of the Os/Os and Os/Ru mixed-valence complexes, Inorg. Chem., 32 (1993) 2827-2834.

[29] D.F. Zigler, Synthesis and Study of Polyazine Bridged Mixed Metal Dyads: Electrochemical, Photophysical, and Photochemical Properties of a New Supramolecular Architecture, Chemistry, Virginia Polytechnic Institute and State University, Blacksburg, VA, 2008.

[30] R.M. Berger, Excited-state absorption spectroscopy and spectroelectrochemistry of tetrakis(2,2'bipyridine)( $\mu$-2,3-bis(2-pyridyl)pyrazine)diruthenium(II) and its mononuclear counterpart: A comparative study, Inorg. Chem., 29 (1990) 1920-1924.

[31] K. Hanson, M.K. Brennaman, A. Ito, H. Luo, W. Song, K.A. Parker, R. Ghosh, M.R. Norris, C.R.K. Glasson, J.J. Concepcion, R. Lopez, T.J. Meyer, Structure-Property Relationships in Phosphonate- 
Derivatized, Ru ${ }^{\mathrm{II}}$-Polypyridyl Dyes on Metal Oxide Surfaces in an Aqueous Environment, J. Phys. Chem. C, 116 (2012) 14837-14847.

[32] S.E. Bettis, D.M. Ryan, M.K. Gish, L. Alibabaei, T.J. Meyer, M.L. Waters, J.M. Papanikolas, Photophysical Characterization of a Helical Peptide Chromophore-Water Oxidation Catalyst Assembly on a Semiconductor Surface Using Ultrafast Spectroscopy, J. Phys. Chem. C, 118 (2014) 6029-6037.

[33] A. Yoshimura, M.Z. Hoffman, H. Sun, An evaluation of the excited-state absorption-spectrum of $\mathrm{Ru}(\mathrm{bpy})_{3}{ }^{(2+)}$ in aqueous and acetonitrile solutions, J. Photochem. Photobiol. A Chem., 70 (1993) 29-33.

[34] Y. Tachibana, J.E. Moser, M. Grätzel, D.R. Klug, J.R. Durrant, Subpicosecond interfacial charge seperation in dye-sensitized nanocrystalline titanium dioxide films, J. Phys. Chem., 100 (1996) 2005620062.

[35] D.F. Zigler, Z.A. Moreseth, L. Wang, D.L. Ashford, M.K. Brennaman, E.M. Grumstrup, E.C. Brigham, M.K. Gish, R.J. Dillon, L. Alibabaei, G.J. Meyer, T.J. Meyer, J.M. Papanikolas, Disentangling the Physical Processes Responsible for the Kinetic Complexity in Interfacial Electron Transfer of Excited $\mathrm{Ru}$ (II) Polypyridyl Dyes on $\mathrm{TiO}_{2}$ J. Am. Chem. Soc., 138 (2016) 4426-4438.

[36] G. Kew, K. DeArmond, K. Hanck, Electrochemistry of Rhodium-Dipyridyl Complexes, J. Phys. Chem., 78 (1974) 727-734.

[37] P. Paul, B. Tyagi, A. K. Bilakhiya, M. M. Bhadbhade, E. Suresh, Stable mononuclear rhodium(II) polypyridyl complexes: synthesis, spectroscopic and structural characterisation, J. Chem. Soc., Dalton Trans., (1999) 2009-2014.

[38] An additional component with 130 to 200 ps time constant (10-20\%) likely arises due to the larger structure and associated differences in vibrational relaxation. The $\sim 150 \mathrm{ps}$ component for $(\mathbf{R u B})_{\mathbf{2}} \mathbf{R h}$ not seen in RuBRh could be due to the additional LA-BL subunit attached to the Rh center in the trimetallic (Section S3), which could also explain the difference between the kinetics of $\mathbf{O s B R h}$ and $(\mathbf{O s B})_{2} \mathbf{R h}$ (Fig. S5).

[39] B.S. Brunschwig, C. Creutz, N. Sutin, Electroabsorption spectroscopy of charge transfer states of transition metal complexes, Coord. Chem. Rev., 177 (1998) 61-79.

[40] G.B. Shaw, D.J. Styers-Barnett, E.Z. Gannon, J.C. Granger, J.M. Papanikolas, Interligand Electron Transfer Dynamics in $\left[\mathrm{Os}(\mathrm{bpy})_{3}\right]^{2+}$ : Exploring the Excited State Potential Surfaces with Femtosecond Spectroscopy, J. Phys. Chem. A, 108 (2004) 4998-5006.

[41] R. Seidel, M. Faubel, B. Winter, J. Blumberger, Single-Ion Reorganization Free Energy of Aqueous $\mathrm{Ru}(\mathrm{bpy})_{3}{ }^{2+/ 3+}$ and $\mathrm{Ru}\left(\mathrm{H}_{2} \mathrm{O}\right)_{6}{ }^{2+/ 3+}$ from Photoemission Spectroscopy and Density Functional Molecular Dynamics Simulation, J. Am. Soc. Chem., 131 (2009) 16127-16137.

[42] K. Nozaki, K. Takamori, Y. Nakatsugawa, T. Ohno, Theoretical Studies of Phosphorescence Spectra of Tris(2,2‘-bipyridine) Transition Metal Compounds, Inorg. Chem., 45 (2006) 6161-6178.

[43] P.S. Wagenknecht, P.C. Ford, Metal centered ligand field excited states: Their roles in the design and performance of transition metal based photochemical molecular devices, Coord. Chem. Rev., 255 (2011) 591-616. 
[44] L.J. McClure, P.C. Ford, Ligand macrocycle effects on the photophysical properties of rhodium(III) complexes: a detailed investigation of cis- and trans-dicyano(1,4,8,11tetraazacyclotetradecane)rhodium(III) and related species, J. Phys. Chem., 96 (1992) 6640-6650.

[45] J.F. Endicott, M.A. Watzky, X.Q. Song, T. Buranda, Observations implicating vibronic coupling in covalently linked transition metal electron transfer systems, Coord. Chem. Rev., 159 (1997) 295-323.

[46] C. Chiorboli, M.A.J. Rodgers, F. Scandola, Ultrafast Processes in Bimetallic Dyads with Extended Aromatic Bridges. Energy and Electron Transfer Pathways in Tetrapyridophenazine-Bridged Complexes, J. Am. Soc. Chem., 125 (2003) 483-491.

[47] P.G. Giokas, S.A. Miller, K. Hanson, M.R. Norris, C.R.K. Glasson, J.J. Concepcion, S.E. Bettis, T.J. Meyer, A.M. Moran, Spectroscopy and Dynamics of Phosphonate-Derivatized Ruthenium Complexes on $\mathrm{TiO}_{2}$, J. Phys. Chem. C, 117 (2013) 812-824. 
